\title{
RNA Interference, Transposon Silencing, and Cosuppression in the Caenorhabditis elegans Germ Line: Similarities and Differences
}

\author{
V.J.P. Robert, N.L. VAstenhouw, and R.H.A. Plasterk \\ Hubrecht Laboratory, 3584 CT Utrecht, The Netherlands
}

Like all genomes analyzed to date, the Caenorhabditis elegans genome contains numerous transposable elements (or remnants of them); in C. elegans, only the DNA transposons have remained active. Jumping of these elements can be frequently detected in the soma but not in the germ line of the most studied lab strain Bristol N2 (Emmons and Yesner 1984). Nevertheless, in some natural isolates, such as Bergerac, transposition also occurs in the germ line (Moerman and Waterston 1984; Eide and Anderson 1985; Collins et al. 1987). In addition, it is possible after mutagenesis to recover lines from Bristol N2 in which germ line transposition occurs (Ketting et al. 1999; Tabara et al. 1999). Taken together, these observations suggest that, in the $C$. elegans germ line, an active system of regulation exists to silence transposition.

Besides these naturally occurring repeated sequences, it is also possible to create artificial repetitive sequences, by microinjecting DNA into the germ line (Stinchcomb et al. 1985). Upon injection, DNA is rearranged to form extrachromosomal transgenic arrays, carrying hundreds of copies of the injected sequence. The sequences present in the array are rapidly silenced in the germ line but not in the soma. Moreover, if the injected DNA (1) shares sequences with an endogenous germ-line-expressed gene and (2) is under the control of an active promoter, the expression of the endogenous locus can also be silenced. This trans-silencing, named "cosuppression," phenocopies a loss-of-function allele of the targeted gene (Dernburg 2000; Ketting and Plasterk et al. 2000).

Here, we describe how the mechanisms of transposon silencing and cosuppression are related to each other and to experimental dsRNA-induced posttranscriptional gene silencing, known as RNA interference (RNAi) (Fire et al. 1998; Dernburg et al. 2000; Ketting and Plasterk 2000). Moreover, we present recent data that address the relation between transposon silencing and RNAi. Finally, we present the phenotypic analysis of $p p w-2$, a gene found to be involved in transposon silencing and cosuppression.

\section{COMMON GENES INVOLVED IN RNAi, TRANSPOSON SILENCING, COSUPPRESSION, AND TRANSGENE SILENCING}

Forward genetic screens have been performed in Craig Mello's group (Tabara et al. 1999) and in ours
(Ketting et al. 1999) to identify RNAi-deficient (rde) and mutator (mut) genes, which are involved in RNAi and transposon silencing, respectively. Surprisingly, it turned out that the results from these screens were partially overlapping, since genes such as mut-7, mut-15 (also known as rde-5; R. Ketting et al., unpubl.), mut-16, and $r d e-2$ (also known as mut-8; B. Tops et al., unpubl.) were identified in both screens (Fig. 1). It is interesting to note that silencing of all active types of transposon is deregulated in these mutants, suggesting that these genes are involved in a general mechanism regulating all transposable elements. Further investigation demonstrated that these same genes are also involved in cosuppression (Ketting and Plasterk 2000), thus these genes required for RNAi, transposon silencing, and cosuppression can be referred to as $m u t / r d e / c d e$ ( $c d e=c o s u p p r e s s i o n ~ d e f e c-$ tive) genes.

For the first time, these results established the existence of a mechanistic link between RNAi, transposon silencing, and cosuppression, but molecular characterization of the different steps and intermediary products involved in those silencing processes was necessary to establish the nature of this link.

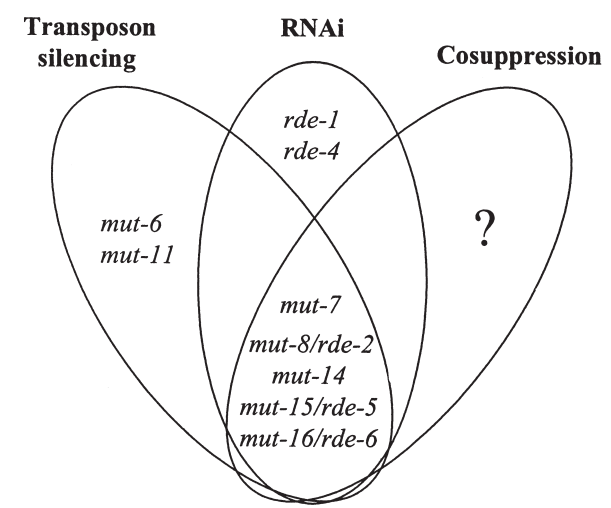

Figure 1. RNAi, transposon silencing, and cosuppression are related but distinct mechanisms. Two independent forward screens were performed to identify rde and mut genes. The results partially overlap, suggesting that RNAi and transposon silencing are related processes. Specific rde and mut genes have also been identified in those screens, showing that these mechanisms are nevertheless distinct. Interestingly, the rde/mut genes are also required for cosuppression. 


\section{RNAi IS A POSTTRANSCRIPTIONAL GENE-SILENCING PHENOMENON INDUCED BY A dSRNA MOLECULE AND MEDIATED BY SiRNAs}

RNAi is the posttranscriptional experimental silencing of genes following the introduction of double-stranded RNA (dsRNA) molecules that share sequence similarity with the targeted gene(s). RNAi was discovered by Andrew Fire, Craig Mello, and their collaborators in C. elegans (Fire et al. 1998). Since then, this mechanism has been shown to be conserved in numerous organisms such as protozoa (Ngo et al. 1998), arthropods (Kennerdell and Carthew 1998), mammals (Wianny and Zernicka-Goetz 2000), and plants (Waterhouse et al. 1998). Its mechanism has been extensively studied and our understanding has grown so fast that it is now, only a few years after its discovery, possible to present a model of how this process works (Fig. 2).

In $C$. elegans, dsRNA can be introduced into the animal by feeding, soaking, or injection. To become an active interfering agent, the dsRNA needs to be cleaved by the RNase III-related enzyme Dicer (Bernstein et al. 2001; Grishok et al. 2001; Ketting et al. 2001; Knight and Bass 2001) into short interfering agents (or siRNA) (Zamore et al. 2000), which are RNA duplexes of 21-23 nucleotides (nt) in length with characteristic 2-nt 3'-hy-

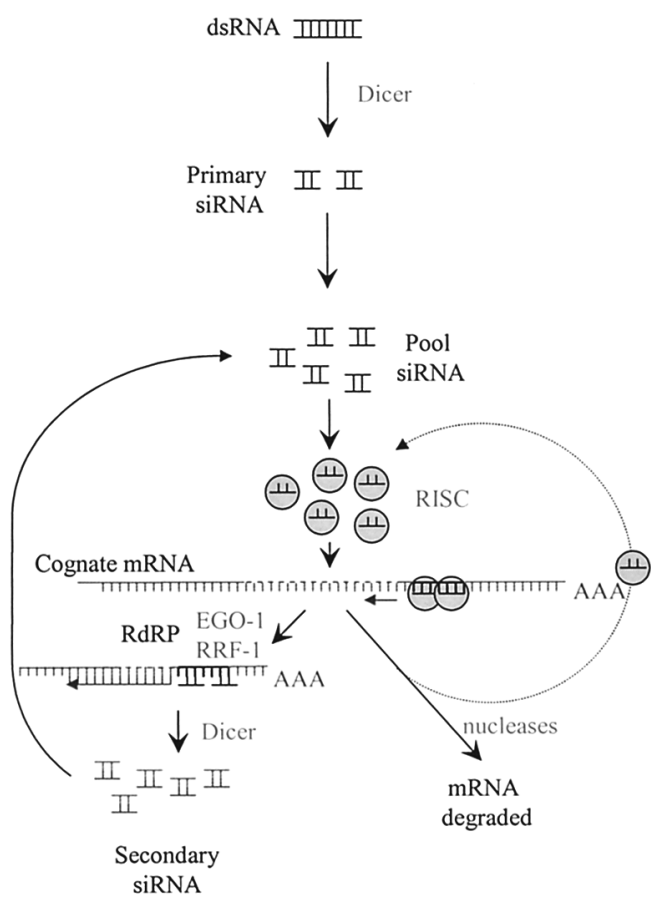

Figure 2. Model for the RNAi mechanism in C. elegans. RNAi is a posttranscriptional gene silencing process triggered by the experimental introduction of dsRNA. The trigger is processed by the RNase III-related enzyme Dicer into short interfering RNA (siRNAs). These interfering agents induce degradation of cognate mRNAs. Several factors involved in this degradation have been identified but it is still unknown whether they defined a single pathway or several ones. Our working model is that mRNA degradation is mediated by the RISC either directly or following amplification by RdRPs. droxyl overhanging ends and 5 '-phosphate termini (Elbashir et al. 2001). They are the active agents inducing the degradation of cognate mRNAs. It has been suggested that siRNAs directly produced from the dsRNA trigger can trigger RNA-dependent RNA polymerases (RdRPs) to transform the mRNA into a new dsRNA molecule (Sijen et al. 2001), which can subsequently be processed by dsRNA-specific nucleases. Genes encoding the RdRPs involved in this pathway have been isolated (Table 1). They are ego-1 (Smardon et al. 2000) and rrf-1 (Sijen et al. 2001), involved in RNAi in the germ line and the soma, respectively. Secondary siRNAs are potentially produced by this pathway and can be incorporated into the general pool of siRNAs. Alternatively, siRNAs are also proposed to be assembled into a ribonucleoprotein complex, known as RISC (RNA-induced silencing complex) (Hammond et al. 2000), which mediates the endonucleolytic cleavage of the cognate mRNA, as an initial event for further exonucleolytic degradation. In Drosophila and human cells (see, e.g., Hutvagner and Zamore 2002; Martinez et al. 2002), such a complex has been isolated and it has recently been reported to have a 5'-phosphomonoester-producing RNA endonuclease activity (Martinez and Tuschl 2004; Schwarz et al. 2004). In C. elegans, a RISC-like structure is thought to exist because most of the Drosophila and human components of RISC are conserved (Caudy et al. 2003), but it has not been isolated yet. At this point, it is difficult to figure out how RdRPs and RISC are connected. In our working model (Fig. 2), all the siRNA are assembled in RISC and those complexes mediate direct or indirect (via RdRPs) mRNA degradation. Further biochemical studies are necessary to test this model.

\section{RNAi-LIKE PTGS IS INVOLVED IN TRANSPOSON SILENCING}

The "cut-and-paste" transposition mechanism (van Luenen et al. 1994) has been extensively studied for Tcl (Emmons et al. 1983) and Tc3 (Collins et al. 1989), the most active transposable elements in C. elegans genome. They both belong to the Tc1/mariner superfamily and contain a single gene (encoding a transposase enzyme) flanked by terminal inverted repeats (TIRs). Their transposition is mediated by self-encoded transposases that specifically recognize their TIRs and induce a doublestrand break of the genomic DNA necessary for the excision/reintegration of the transposon (Vos et al. 1996). Their transposition is tightly regulated in the germ line, and the first chemically induced genetic mutants in which increased germ line transposition can be detected were reported more than 15 years ago (Collins et al. 1987). Our understanding of this regulatory mechanism has significantly improved only recently, after the establishment of its link with RNAi mechanism (Ketting et al. 1999; Tabara et al. 1999).

By analogy with what is known for RNAi, dsRNA molecules expressed from transposons have been searched for in $C$. elegans strains. DsRNA molecules have been detected for Tc1, Tc3, and Tc5 (Sijen and Plas- 
GENE SILENCING IN C. ELEGANS

Table 1. Examples of Genes Involved in Silencing Processes in C. elegans

\begin{tabular}{|c|c|c|c|c|c|c|}
\hline Class & Gene name & Brief description & Identification $^{a}$ & mut & $r d e$ & cde \\
\hline mut/rde & mut-7 & Nuclease & EMS screen $^{1}$ & + & $+^{\mathrm{b}}$ & $++^{14,15}$ \\
\hline \multirow[t]{6}{*}{ lcde } & mut-14 & RNA helicase & EMS screen ${ }^{1,2}$ & + & + & + \\
\hline & mut-16 & PolyQ & EMS screen ${ }^{1} /$ RNAi screen 3 & + & + & + \\
\hline & $p p w-2$ & Argonaute & RNAi screen ${ }^{4}$ & + &,+- & + \\
\hline & mut-2 & Not cloned yet & EMS screen $^{5}$ & + & + & $+{ }^{14}$ \\
\hline & rde-2/mut -8 & B. Tops et al., unpubl. & EMS screen ${ }^{1,6}$ & + & $+^{\mathrm{a}}$ & $++^{14,15}$ \\
\hline & mut-15 & R. Ketting et al., unpubl. & EMS screen ${ }^{1}$ & + & + & + \\
\hline \multirow[t]{3}{*}{ rde } & $r d e-4$ & DsRNA binding & EMS screen ${ }^{6,7}$ & - & + & - \\
\hline & $r d e-1$ & Argonaute & EMS screen $^{6}$ & - & + & -14,15 \\
\hline & $p p w-1$ & Argonaute & Natural isolate ${ }^{8}$ & - & $+^{\mathrm{b}}$ & - \\
\hline \multirow[t]{2}{*}{ mut } & mut-6 & Not cloned yet & Spontaneous ${ }^{16}$ & + & - & ${ }^{14}$ \\
\hline & mut-11 & Not cloned yet & EMS screen ${ }^{1}$ & + & _ & - \\
\hline still not & $d c r-1$ & Nuclease & Reverse genetics ${ }^{9-11}$ & $?$ & + & ? \\
\hline \multirow[t]{3}{*}{ classified } & $r d e-3$ & Not cloned yet & EMS screen $^{6}$ & + & + & ? \\
\hline & ego-1 & RdRP & EMS screen $^{12}$ & ? & $+^{\mathrm{b}}$ & ? \\
\hline & $r r f-1$ & RdRP & Reverse genetics ${ }^{13}$ & - & $+^{\mathrm{c}}$ & $?$ \\
\hline
\end{tabular}

+ and - indicate that the gene is involved in the considered silencing process.

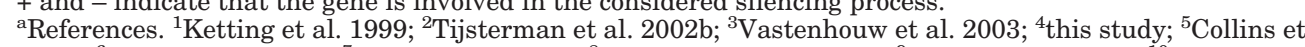
al. 1987; ${ }^{6}$ Tabara et al. $1999 ;{ }^{7}$ Tabara et al. $2002 ;{ }^{8}$ Tijsterman et al. 2002a; ${ }^{9}$ Ketting et al. $2001 ;{ }^{10}$ Knight and Bass 2001; ${ }^{11}$ Grishok et al. 2001; ${ }^{12}$ Smardon et al. 2000; ${ }^{13}$ Sijen et al. 2001; ${ }^{14}$ Ketting and Plasterk 2000; ${ }^{15}$ Dernburg et al. 2000; ${ }^{16}$ Mori et al. 1988.

${ }^{\mathrm{b}}$ Germ line specific

${ }^{\mathrm{c} S o m a ~ s p e c i f i c . ~}$

terk 2003). They are derived from the TIR sequences. This finding implies that transposon transcripts form dsRNA intramolecularly by snapping back into a panhandle structure. A low amount of Tc1-siRNAs-like molecules, 20-27 nt in length, were detected in wild-type (WT) and rde (non mut) background animals. They are (almost) absent in mut/rde/cde and mut backgrounds, are mostly derived from the TIR sequences, and are assumed to be produced by a Dicer-mediated degradation of the TIR dsRNA molecules.

To test whether the detected Tc1-siRNA molecules could induce silencing, TIR sequences were fused to the $g f p$ reporter gene in a construct designed to be expressed in the germ line. This chimaeric construct introduced in low copy number in a WT background is indeed silenced. This silencing is directly dependent on TIR sequences, since similar transgenes are normally expressed when unrelated sequences replace the Tc1 TIR sequences. In addition, Tc1 TIR sequences induce silencing only if they are present in the transcribed sequences, strongly suggesting that the observed silencing occurs at the posttranscriptional level. Finally, the silencing induced by Tc1 TIR sequences is dependent on mut/rde/cde genes. Comparison of the ratio spliced-to-unspliced $g f p$-Tc 1 transcripts in context where these transgenes are silenced or not, confirms that, as previously demonstrated, a posttranscriptional component is involved in their silencing. The presence of Tc1 dsRNA and Tc1 siRNA as well as the observation that transgenes carrying Tc1 sequences are posttranscriptionally silenced in a mut/rde/cde genesdependent way strongly suggest that transposons are silenced at the posttranscriptional level and that Tc1siRNAs mediate this silencing.

Similar studies aimed at cosuppression have been difficult, as loss of germ-line-expressed genes usually strongly affects the fertility or viability of $C$. elegans. To circumvent this problem, we developed fertile strains in which a $g f p$ reporter gene expressed in the germ line is cosuppressed by the presence of multiple copies of $g f p$. These lines are now analyzed to establish cosuppression requirements and identify molecular intermediaries and genes involved in cosuppression (V. Robert et al., unpubl.).

\section{IDENTIFICATION OF GENES INVOLVED IN SILENCING PROCESSES IN C. ELEGANS}

Forward and genetics screens have been performed to identify genes involved in silencing processes in C. elegans (Collins et al. 1987; Ketting et al. 1999; Tabara et al. 1999; Dudley et al. 2002; Vastenhouw et al. 2003). They established the existence of $m u t / r d e / c d e$ genes as well as the existence of specific mut and $r d e$ genes. In addition, we carried out an Ethyl Methane Sulfonate (EMS) mutagenesis for $c d e$ genes (Fig. 3) (V. Robert and R. Plasterk, unpubl.). We have recovered mutants of $m u t / r d e / c d e$ genes, but also found mutants affecting some, but not all, phenomena. A short list of some of the genes is given in Table 1. To analyze the relationship between the different silencing processes, we classified them according to their involvement in RNAi, transposon silencing, and cosuppression.

Three $m u t / r d e / c d e$ genes have been identified at the molecular level so far (Table 1): mut-7 encodes a RNaseD domain-containing protein (Ketting et al. 1999); mut-14, a putative RNA helicase (Tijsterman et al. 2002b); and mut-16, a protein with a polyglutamine domain (Vastenhouw et al. 2003). How could these factors act in the silencing process? One possibility is that they are required for a step common to all silencing processes. Alternatively, the mut $/ r d e / c d e$ genes could encode components of the backbone of complex(es) common to all silencing 
$\mathbf{A}$

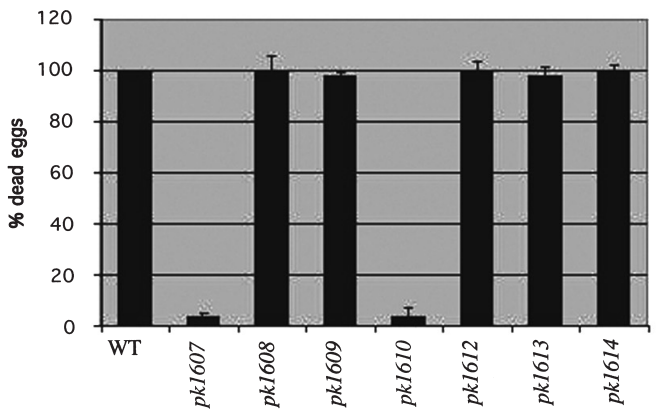

B

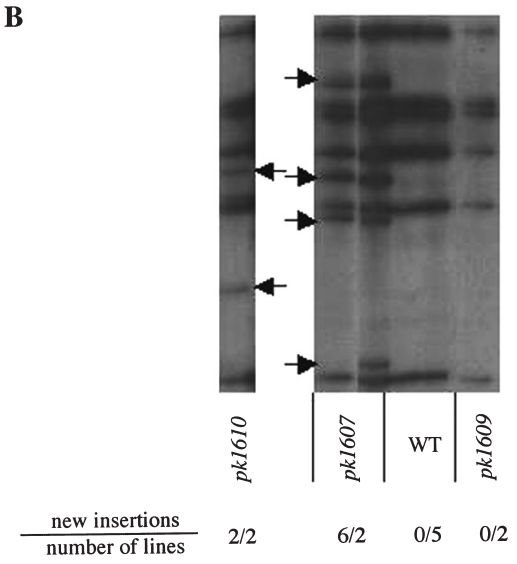

Figure 3. An EMS mutagenesis revealed the existence of specific cde genes. Analysis of seven cde mutants isolated in an EMS screen were studied for their RNAi competence by their capacity to resist targeting of pos-1, a gene required for embryonic viability $(A)$. Pk1607 and pk1610 are also affected in RNAi. In addition, Tc1 silencing deregulation was observed by transposon insertion display in $p k 1607$ and $p k 1610$ genetic backgrounds. (B) These alleles belong to $m u t / r d e / c d e$ complementation groups. In contrast, Tc1 is still silenced in a pk1609 background and this allele is still RNAi sensitive. Thus pk1609 is an allele of a not-yet-cloned specific $c d e$ gene.

processes, whose specificity would be defined by their association with specific RDE, MUT, or CDE factors or siRNAs. To test this, biochemical characterization of (ribonucleo)protein complexes involved in silencing processes (in C. elegans) is now necessary.

\section{THE Argonaute GENES ARE WIDELY CONSERVED AND INVOLVED IN SILENCING PROCESSES IN MANY ORGANISMS}

The Argonaute proteins are defined by the presence of two conserved domains named PAZ and PIWI (Cerutti et al. 2000). For example, these proteins have been found in Arabidopsis thaliana, C. elegans, Drosophila melanogaster, and mammals (for review, see Carmell et al. 2002). Some of these proteins (the piwi subfamily as defined by Carmell et al. [2002]) have been shown to play an essential role in stem cell fate (Cox et al. 1998). In addition, they have been implicated in a variety of homology-dependent mechanisms that involve small RNAs and induce transcriptional (see, e.g., Pal-Bhadra et al. 2002; Zilberman et al. 2003; Verdel et al. 2004), posttranscriptional (see, e.g., Tabara et al. 1999; Tijsterman et al. 2002a), or translational (see, e.g., Grishok et al. 2001; Vaucheret et al. 2004) gene silencing. Moreover, the Schizosaccharomyces pombe (Hall et al. 2003) and Trypanosoma brucei (Durand-Dubief and Bastin 2003) Argonaute proteins are required for chromosome segregation. The connection between these mechanisms and the maintenance of stem cells is still not clearly established.

Three-dimensional nuclear magnetic resonance (Lingel et al. 2003) and crystal (Song et al. 2003; Yan et al. 2003; Ma et al. 2004) structures of PAZ domains have been reported. They suggest that PAZ is a conserved RNA-binding domain, which might play as a siRNA-endbinding module, and that the Argonaute proteins could be shuttles, which drive siRNAs between the different ribonucleoprotein complexes involved in silencing processes. In agreement with this model, Argonaute proteins have been found in siRNAs-containing ribonucleoprotein complexes in Drosophila (Hammond et al. 2001), Neurospora crassa (Catalanotto et al. 2002), S. pombe (Verdel et al. 2004), and human (Martinez et al. 2002).

\section{THE Argonaute FAMILY AND SILENCING PROCESSES IN C. ELEGANS}

$R d e-1$ is the first Argonaute gene to have been implicated in RNAi (Tabara et al. 1999). It is encoded, together with 29 other Argonaute proteins, by the C. elegans genome. Its function seems to be restricted to RNAi. RDE-1 has been found to interact with RDE-4, a dsRNA binding protein, Dicer, and the RNA helicase DRH-1 (Tabara et al. 2002). It has been proposed that this complex could have a role in selecting and processing doublestranded RNA molecules for the RNAi pathway.

Additional Argonaute genes have been found to be involved in silencing processes in C. elegans. First, alg-1 and alg-2 (Grishok et al. 2001), together with $d c r-1$, are both required for maturation of the small temporal RNA lin-4, and $\operatorname{lig}-2$, at least, is required for maturation of the small temporal RNA let-7. Second, $p p w-1$ (Tijsterman et al. 2002a) is required for RNAi in the germ line but not in the soma, while transposon silencing is still efficient in a genetic background where $p p w-1$ is deleted (Tijsterman et al. 2002a; V. Robert and R. Plasterk, unpubl.). Third, RNAi screens performed to identify genes involved in transposon silencing (Vastenhouw et al. 2003) and cosuppression (V. Robert et al, unpubl.) showed that $p p w-2$ is required for both transposon silencing and cosuppression and that two other members of the Argonaute family are implicated in cosuppression.

To further investigate the involvement of $p p w-2$ in silencing processes, we isolated and analyzed the deletion pk1673 covering a large region of $p p w-2$, including the PAZ and the PIWI domains. Ppw-2(pk1673) homozygous animals exhibit a cde/mut phenotype and a partial 


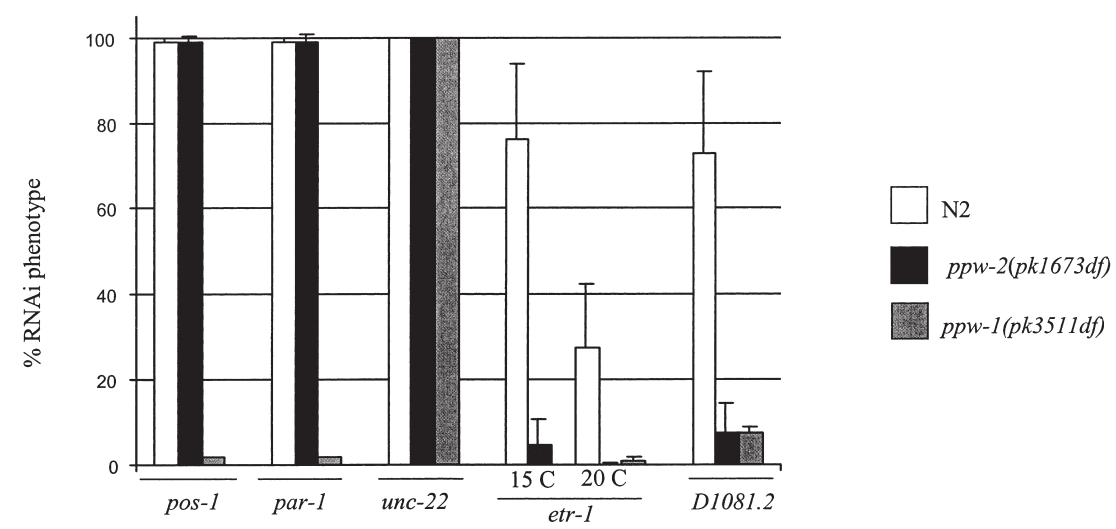

Figure 4. $p p w-2$ and RNAi. N2 animals, homozygotes for $p k 1673(p p w-2)$ and homozygotes for $p k 3511$ (ppw-1) were assayed for their sensitivity to RNAi. Animals were fed for $48 \mathrm{hr}$ at $15^{\circ} \mathrm{C}$ with food expressing dsRNA targeting specific C. elegans genes. They were then singled onto fresh targeting foods for $24 \mathrm{hr}$ at $20^{\circ} \mathrm{C}$. Adults were eliminated and progeny was allowed to develop at $20^{\circ} \mathrm{C}$. Embryonic and postembryonic phenotypes were scored after 24 and $48 \mathrm{hr}$. The targeted gene is indicated below the graph. Scored phenotypes: for pos- 1 and par-1, dead embryos; for unc-22, twitching animals; and for etr-1 and D1081.2, body abnormalities. For etr1 , two independent assays, respectively carried out at $15^{\circ} \mathrm{C}$ and $20^{\circ} \mathrm{C}$, are shown. Between two and ten animals were scored in each assay. Standard deviation is indicated.

rde phenotype (Fig. 4): Depending on the gene targeted by RNAi, it appears that $p p w-2$ (pk1673) homozygotes behave as wild type (Fig. 4, RNAi targeting genes pos-1, par-1, and unc-22) or as a mutant (Fig. 4, targeting genes etr-1 and D1081.2). Strikingly, RNAi known to induce a complete loss of function of the targeted gene (for example, against pos-1, par- 1 , and unc-22) seems to remain efficient in the absence of PPW-2, whereas RNAi known to induce partial loss of function of the targeted gene (e.g., targeting etr-1 and D1081.2) seems to require PPW-2. In this latter case, we assume that less siRNA are available and we propose that PPW-2 is necessary to make them active (for instance, by processing them or by targeting them to an RDE complex). In transposon silencing, which seems to be mediated by Tc1 siRNA produced from endogenous Tc1 dsRNA molecules, PPW-2 could play a similar role and be required, possibly because the Tc1 siRNA are not abundant. In agreement with this hypothesis, Tc1 siRNAs can still be detected in $p p w-2(p k 1673)$ animals (data not shown), suggesting that $p p w-2$ acts downstream of the production of Tc1 siRNA.

\section{CONCLUSIONS}

Many factors involved in silencing processes have now been identified. Genetic analysis indicates that on the one hand the three silencing phenomena (RNAi, transposon silencing, and cosuppression) have much in common, while on the other hand some mutations affect one process but not the others. This may indicate that specialized complexes carry out each of these silencing phenomena.

\section{ACKNOWLEDGMENTS}

We thank Dr. René Ketting and Dr. Robin May for critical reading of the manuscript.

\section{REFERENCES}

Bernstein E., Caudy A.A., Hammond S.M., and Hannon G.J. 2001. Role for a bidentate ribonuclease in the initiation step of RNA interference. Nature 409: 363.

Carmell M.A., Xuan Z., Zhang M.Q., and Hannon G.J. 2002. The Argonaute family: Tentacles that reach into RNAi, developmental control, stem cell maintenance, and tumorigenesis. Genes Dev. 16: 2733.

Catalanotto C., Azzalin G., Macino G., and Cogoni C. 2002. Involvement of small RNAs and role of the qde genes in the gene silencing pathway in Neurospora. Genes Dev. 16: 790.

Caudy A.A., Ketting R.F., Hammond S.M., Denli A.M., Bathoorn A.M., Tops B.B., Silva J.M., Myers M.M., Hannon G.J., and Plasterk R.H. 2003. A micrococcal nuclease homologue in RNAi effector complexes. Nature 425: 411.

Cerutti L., Mian N., and Bateman A. 2000. Domains in gene silencing and cell differentiation proteins: The novel PAZ domain and redefinition of the Piwi domain. Trends Biochem. Sci. 25: 481.

Collins J., Forbes E., and Anderson P. 1989. The Tc3 family of transposable genetic elements in Caenorhabditis elegans. Genetics 121: 47.

Collins J., Saari B., and Anderson P. 1987. Activation of a transposable element in the germ line but not the soma of Caenorhabditis elegans. Nature 328: 726.

Cox D.N., Chao A., Baker J., Chang L., Qiao D., and Lin H. 1998. A novel class of evolutionarily conserved genes defined by piwi are essential for stem cell self-renewal. Genes Dev. 12: 3715 .

Dernburg A.F., Zalevsky J., Colaiacovo M.P., and Villeneuve A.M. 2000. Transgene-mediated cosuppression in the C. elegans germ line. Genes Dev. 14: 1578.

Dudley N.R., Labbe J.C., and Goldstein B. 2002. Using RNA interference to identify genes required for RNA interference. Proc. Natl. Acad. Sci. 99: 4191

Durand-Dubief M. and Bastin P. 2003. TbAGO1, an Argonaute protein required for RNA interference, is involved in mitosis and chromosome segregation in Trypanosoma brucei. BMC Biol. 1: 2

Eide D. and Anderson P. 1985. Transposition of Tc1 in the nematode Caenorhabditis elegans. Proc. Natl. Acad. Sci. 82: 1756.

Elbashir S.M., Lendeckel W., and Tuschl T. 2001. RNA interference is mediated by $21-$ and 22 -nucleotide RNAs. Genes Dev. 15: 188 . 
Emmons S.W. and Yesner L. 1984 High-frequency excision of transposable element Tc 1 in the nematode Caenorhabditis elegans is limited to somatic cells. Cell 36: 599.

Emmons S.W., Yesner L., Ruan K.S., and Katzenberg D. 1983. Evidence for a transposon in Caenorhabditis elegans. Cell 32: 55.

Fire A., Xu S., Montgomery M.K., Kostas S.A., Driver S.E., and Mello C.C. 1998. Potent and specific genetic interference by double-stranded RNA in Caenorhabditis elegans. Nature 391: 806 .

Grishok A., Pasquinelli A.E., Conte D., Li N., Parrish S., Ha I., Baillie D.L., Fire A., Ruvkun G., and Mello C.C. 2001. Genes and mechanisms related to RNA interference regulate expression of the small temporal RNAs that control C. elegans developmental timing. Cell 106: 23.

Hall I.M., Noma K., and Grewal S.I. 2003. RNA interference machinery regulates chromosome dynamics during mitosis and meiosis in fission yeast. Proc. Natl. Acad. Sci. 100: 193.

Hammond S.M., Bernstein E., Beach D., and Hannon G.J. 2000. An RNA-directed nuclease mediates post-transcriptional gene silencing in Drosophila cells. Nature 404: 293.

Hammond S.M., Boettcher S., Caudy A.A., Kobayashi R., and Hannon G.J. 2001. Argonaute2, a link between genetic and biochemical analyses of RNAi. Science 293: 1146.

Hutvagner G. and Zamore P.D. 2002. A microRNA in a multiple-turnover RNAi enzyme complex. Science 297: 2056.

Kennerdell J.R. and Carthew R.W. 1998. Use of dsRNA-mediated genetic interference to demonstrate that frizzled and frizzled 2 act in the wingless pathway. Cell 95: 1017.

Ketting R.F. and Plasterk R.H. 2000. A genetic link between cosuppression and RNA interference in C. elegans. Nature 404: 296.

Ketting R.F., Haverkamp T.H., van Luenen H.G., and Plasterk R.H. 1999. Mut-7 of C. elegans, required for transposon silencing and RNA interference, is a homolog of Werner syndrome helicase and RNaseD. Cell 99: 133.

Ketting R.F., Fischer S.E., Bernstein E., Sijen T., Hannon G.J., and Plasterk R.H. 2001. Dicer functions in RNA interference and in synthesis of small RNA involved in developmental timing in C. elegans. Genes Dev. 15: 2654.

Knight S.W. and Bass B.L. 2001. A role for the RNase III enzyme DCR-1 in RNA interference and germ line development in C. elegans. Science 2: 2.

Lingel A., Simon B., Izaurralde E., and Sattler M. 2003. Structure and nucleic-acid binding of the Drosophila Argonaute 2 PAZ domain. Nature 426: 465.

Ma J.B., Ye K., and Patel D.J. 2004. Structural basis for overhang-specific small interfering RNA recognition by the PAZ domain. Nature 429: 318.

Martinez J. and Tuschl T. 2004. RISC is a 5 ' phosphomonoesterproducing RNA endonuclease. Genes Dev. 18: 975.

Martinez J., Patkaniowska A., Urlaub H., Luhrmann R., and Tuschl T. 2002. Single-stranded antisense siRNAs guide target RNA cleavage in RNAi. Cell 110: 563.

Moerman D.G. and Waterston R.H. 1984. Spontaneous unstable unc-22 IV mutations in C. elegans var. Bergerac. Genetics 108: 859 .

Mori I., Moerman D.G., and Waterston R.H. 1988 Analysis of a mutator activity necessary for germline transposition and excision of Tc1 transposable elements in Caenorhabditis elegans. Genetics 120: 397.

Ngo H., Tschudi C., Gull K., and Ullu E. 1998. Double-stranded RNA induces mRNA degradation in Trypanosoma brucei. Proc. Natl. Acad. Sci. 95: 14687.

Pal-Bhadra M., Bhadra U., and Birchler J.A. 2002. RNAi related mechanisms affect both transcriptional and posttranscriptional transgene silencing in Drosophila. Mol. Cell 9: 315.

Schwarz D.S., Tomari Y., and Zamore P.D. 2004. The RNA-induced silencing complex is a $\mathrm{Mg} 2+$-dependent endonuclease. Curr. Biol. 14: 787.
Sijen T. and Plasterk R.H. 2003. Transposon silencing in the Caenorhabditis elegans germ line by natural RNAi. Nature 426: 310 .

Sijen T., Fleenor J., Simmer F., Thijssen K.L., Parrish S., Timmons L., Plasterk R.H., and Fire A. 2001. On the role of RNA amplification in dsRNA-triggered gene silencing. Cell 107: 465.

Smardon A., Spoerke J.M., Stacey S.C., Klein M.E., Mackin N., and Maine E.M. 2000. EGO-1 is related to RNA-directed RNA polymerase and functions in germ-line development and RNA interference in C. elegans. Curr. Biol. 10: 169.

Song J.J., Liu J., Tolia N.H., Schneiderman J., Smith S.K., Martienssen R.A., Hannon G.J., and Joshua-Tor L. 2003. The crystal structure of the Argonaute2 PAZ domain reveals an RNA binding motif in RNAi effector complexes. Nat. Struct. Biol. 10: 1026.

Stinchcomb D.T., Shaw J.E., Carr S.H., and Hirsh D. 1985. Extrachromosomal DNA transformation of Caenorhabditis elegans. Mol. Cell. Biol. 5: 3484.

Tabara H., Yigit E., Siomi H., and Mello C.C. 2002. The dsRNA binding protein RDE-4 interacts with RDE-1, DCR-1, and a DExH-box helicase to direct RNAi in C. elegans. Cell 109: 861.

Tabara H., Sarkissian M., Kelly W.G., Fleenor J., Grishok A., Timmons L., Fire A., and Mello C.C. 1999. The rde-1 gene, RNA interference, and transposon silencing in C. elegans. Cell 99: 123.

Tijsterman M., Okihara K.L., Thijssen K., and Plasterk R.H. 2002a. PPW-1, a PAZ/PIWI protein required for efficient germline RNAi, is defective in a natural isolate of C. elegans. Curr. Biol. 12: 1535.

Tijsterman M., Ketting R.F., Okihara K.L., Sijen T., and Plasterk R.H. 2002b. RNA helicase MUT-14-dependent gene silencing triggered in C. elegans by short antisense RNAs. Science 295: 694.

van Luenen H.G., Colloms S.D., and Plasterk R.H. 1994. The mechanism of transposition of Tc3 in C. elegans. Cell 79: 293.

Vastenhouw N.L., Fischer S.E., Robert V.J., Thijssen K.L., Fraser A.G., Kamath R.S., Ahringer J., and Plasterk R.H. 2003. A genome-wide screen identifies 27 genes involved in transposon silencing in C. elegans. Curr. Biol. 13: 1311.

Vaucheret H., Vazquez F., Crete P., and Bartel D.P. 2004. The action of ARGONAUTE1 in the miRNA pathway and its regulation by the miRNA pathway are crucial for plant development. Genes Dev. 18: 1187.

Verdel A., Jia S., Gerber S., Sugiyama T., Gygi S., Grewal S.I., and Moazed D. 2004. RNAi-mediated targeting of heterochromatin by the RITS complex. Science 303: 672 .

Vos J.C., De Baere I., and Plasterk R.H. 1996. Transposase is the only nematode protein required for in vitro transposition of Tc1. Genes Dev. 10: 755.

Waterhouse P.M., Graham M.W., and Wang M.B. 1998. Virus resistance and gene silencing in plants can be induced by simultaneous expression of sense and antisense RNA. Proc. Natl. Acad. Sci. 95: 13959.

Wianny F. and Zernicka-Goetz M. 2000. Specific interference with gene function by double-stranded RNA in early mouse development. Nat. Cell Biol. 2: 70.

Yan K.S., Yan S., Farooq A., Han A., Zeng L., and Zhou M.M. 2003. Structure and conserved RNA binding of the PAZ domain. Nature 426: 468

Zamore P.D., Tuschl T., Sharp P.A., and Bartel D.P. 2000. RNAi: Double-stranded RNA directs the ATP-dependent cleavage of mRNA at 21 to 23 nucleotide intervals. Cell 101: 25.

Zilberman D., Cao X., and Jacobsen S.E. 2003. ARGONAUTE4 control of locus-specific siRNA accumulation and DNA and histone methylation. Science 299: 716. 


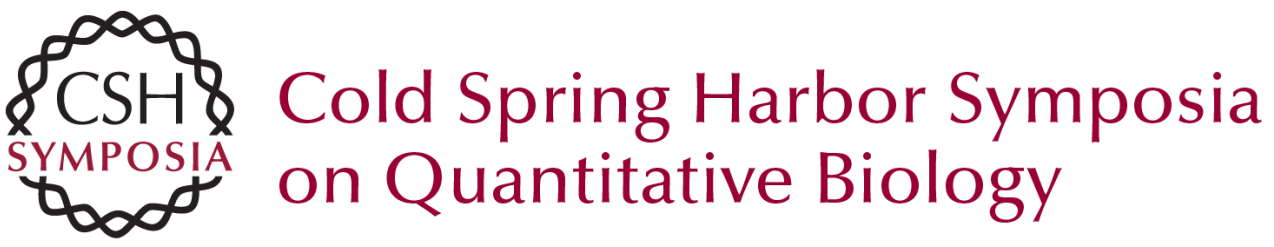

\title{
RNA Interference, Transposon Silencing, and Cosuppression in the Caenorhabditis elegans Germ Line: Similarities and Differences
}

\author{
V.J.P. ROBERT, N.L. VASTENHOUW and R.H.A. PLASTERK
}

Cold Spring Harb Symp Quant Biol 2004 69: 397-402

Access the most recent version at doi:10.1101/sqb.2004.69.397

References This article cites 54 articles, 23 of which can be accessed free at: http://symposium.cshlp.org/content/69/397.full.html\#ref-list-1

\section{License}

Email Alerting Service 